\title{
Studies of Coordinated Zone Protection Strategy for DC Grid
}

\author{
Liangzhong Yao, Jing Wu \\ China Electric Power Research Institute \\ Xiaoying East Road, Beijing, 100192, China \\ j-w13@mails.tsinghua.edu.cn
}

\author{
Lie Xu, Md Habibur Rahman \\ Department of Electronic \& Electrical Engineering \\ University of Strathclyde \\ Glasgow, United Kingdom
}

\begin{abstract}
DC grid technology is one of the effective methods for collecting, transmitting and accommodating large-scale renewable energy over long-distance. Voltage source converter (VSC) based DC grid technology has become a preferred technical scheme because of its inherent advantages, such as flexible bidirectional DC power control capability. However, VSC based DC grid is also facing many operation control and protection problems to be solved, especially the problem of fault protection for the $D C$ grid. This paper first analyzed the fault characteristics of the DC grid, and then through a typical DC grid configuration, a zone protection strategy is proposed with the objective of using a minimum number of DCCBs. The simulation results using MATLAB/Simulink platform show that the zone protection strategy is feasible and effective. The study in this paper provides a technical reference for the research and development of fault protection and isolation for DC grid in the future.
\end{abstract}

Keywords-DC grid; DC fault characteristics; DC circuit breaker; DC zone protection

\section{INTRODUCTION}

With the increasing depletion of fossil energy and the growing pressure on the environment improvement, the world is facing the strategic adjustment of energy structure, to seek a feasible way of transition from traditional energy to renewable energy. However, wind energy, solar energy and other renewable energy power generation is intermittent and random, thus the integration of large-scale renewable energy power will pose new challenges to the safe and stable operation of power grid. In addition, as the maldistribution of energy resources and load centers, the transmission of largescale long-distance power and interconnection of regional AC grid is needed in order to achieve a wide-area assumption of renewable energy and an optimal allocation of energy resources. DC grid technology is one of the most effective methods to solve the above problems [1]. Moreover, VSCHVDC technology is a preferred technical choice for constructing DC grid due to the advantage of bidirectional power flow, no commutation failure, and active/ reactive power fast decoupled control [2].

Even though VSC based DC grid has several advantages, there are several technical challenges that need to be addressed. In particular the protection of a DC grid in the event of a DC fault including the fault location and its isolation [3-5]. The protection system has to be designed in such a way that it can act fast, e.g. within few milliseconds, as the rate of rise of DC fault current is very high due to the low impedance of the DC grid. An effective protection method needs to detect the fault and its location and isolate the faulty line in a selective manner allowing fast restoration of normal system operation following a DC fault [6-7].

There are several protection methods that have been proposed for DC grid [6-8]. A protection method of VSC based DC grid was discussed in [9] in which a 'Handshaking' method using DC switchgear and AC circuit breakers was proposed. But the system recovery is slow which can pose significant operational problems for DC grids and connected $\mathrm{AC}$ grids due to the large loss of infeed. Fast and reliable fault detection and clearance is mandatory to clear the fault on time to avoid the shutdown of the entire systems. With the development of direct current circuit breaker (DCCB) research, fault protection method of using DCCB is being considered to ensure the healthy part of the DC grid can continue operating.

In this paper, DC fault characteristics and zone protection method is analyzed on a typical DC grid configuration. This DC fault protection considers the minimal use of DCCBs for reducing the cost. It concentrates on using the minimum number of fast acting DCCBs at strategic locations to allow the entire MTDC system to be operated interconnected but partitioned into islanded zones following faults so as the healthy part can continue operating. Through MATLAB/Simulink simulation analysis, the effectiveness of the protection method is verified.

\section{DC FAULT BEHAVIOR}

DC faults can cause serious consequences for VSC based DC grids due to the low impedance of the DC network and the existence of the freewheeling diodes in converters. DC faults can be caused by several reasons such as ship anchors for undersea cables or lightening strike in case of overhead lines, physical damage, electrical stress, cable aging and environmental stress [10]. When a DC fault occurs, the current increases significantly due to the discharge of the DC capacitors, AC side current feeding through the freewheeling diodes that can potentially damage the power electronic devices. In case of a DC grid, a single DC fault could potentially bring down the whole DC system and all converter stations connected to the common DC grid would experience 
over-current leading to the complete system being shut down for prolonged period [11]. Primarily, the DC faults that are possible in a DC grid can be categorized as line-to-line fault and line-to-ground fault. As line-to-line fault usually results in higher fault current, thus only the line-to-line fault response is considered in this paper.

Assume a permanent DC line-to-line fault is applied at $1.1 \mathrm{~s}$ and the half bridge MMC converter is blocked $1 \mathrm{~ms}$ after the fault initiation. Fig. 1 shows the equivalent circuit of half bridge MMC and fig. 2 shows the system response during the whole fault period.

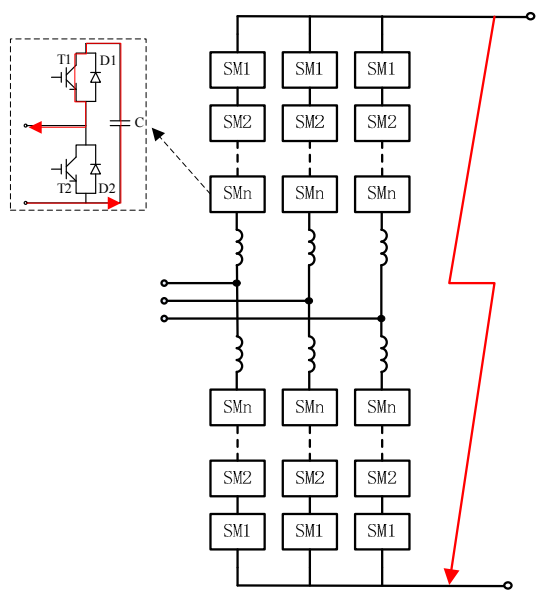

Fig. 1. Equivalent circuits of half bridge MMC during DC line-to-line fault

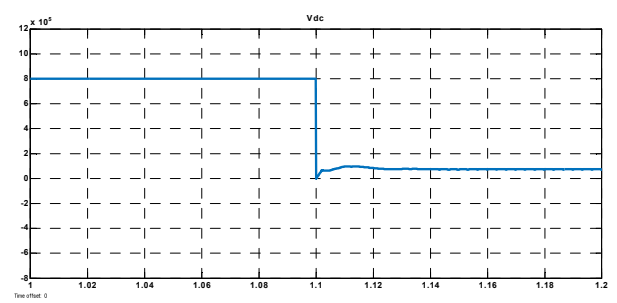

(a) DC link voltage

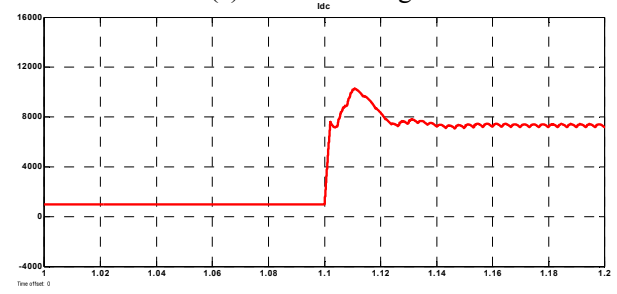

(b) DC link current

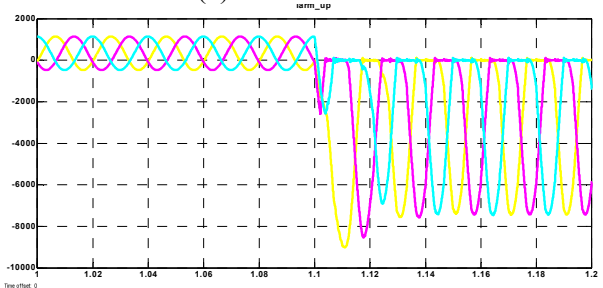

(c) Upper arm current

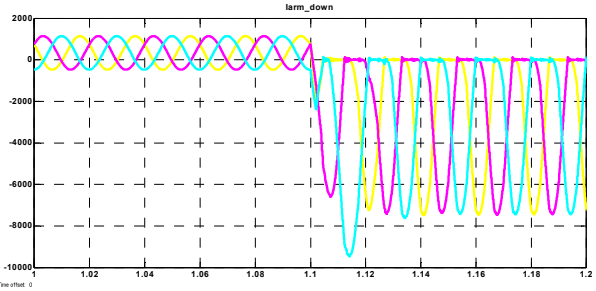

(d) Lower arm current

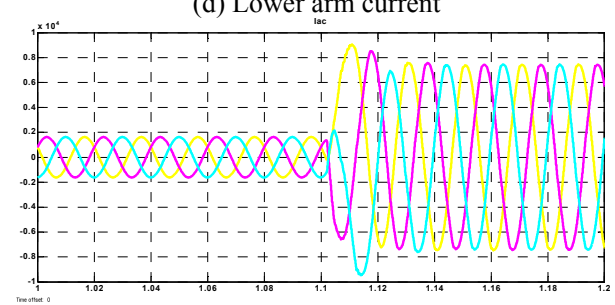

(e) Converter side AC current

Fig. 2. Response from a half bridge MMC during DC line-to-line fault

Fig. 2(a) shows the collapse of the converter DC link voltage with oscillations immediately after the DC line-to-line fault initiation. Fig. 2(b) represents the converter DC currents showing rapid increase. The rising rate is related to the converter transformer leakage inductance and arms reactance. Figs. 2(c) and (d) show the upper and lower arm currents respectively where the arm currents of the converter tend to be negative which confirms that the in-feed currents from the AC to DC side during DC fault are flowing through the antiparallel diodes. Fig. 2(e) and shows large AC currents feeding from the AC grid during the fault.

\section{DC GRID CONFIGURATION AND SiMULATION MODEL}

\section{A. DC grid configuration and parameter}

Different types of configuration can be arranged for DC grids in accordance with the requirements of power collection and transmission, while resulting in different requirements for the system model, control and protection scheme as well. For a practical DC grid, the system configuration is mainly depending on the locations of the converter stations and the requirements for the safe and reliable operation of DC grids. Figure 3 shows a typical 5-terminal DC grid.

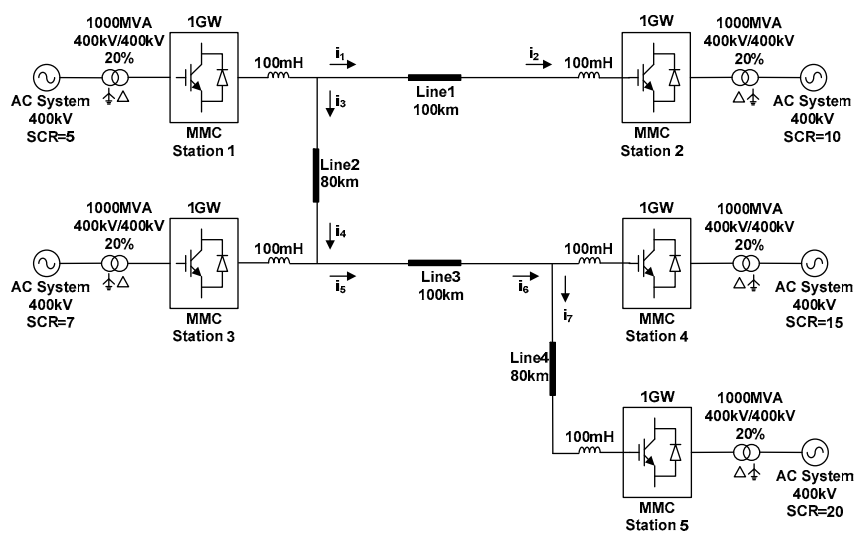

Fig. 3. Configuration of 5-terminal DC grid 
TABLE I. MAIN PARAMETERS OF 5-TERMINAL DC GRID

\begin{tabular}{|c|c|c|}
\hline \multirow{4}{*}{ MMC parameter } & rated power & $1000 \mathrm{MW}$ \\
\cline { 2 - 3 } & DC voltage & $800 \mathrm{kV}( \pm 400 \mathrm{kV})$ \\
\cline { 2 - 3 } & AC voltage & $400 \mathrm{kV}$ \\
\cline { 2 - 3 } & AC frequency & $50 \mathrm{~Hz}$ \\
\hline \multirow{4}{*}{ resistance } & $0.009 \Omega / \mathrm{km}$ \\
\cline { 2 - 3 } & inductance & $1.4 \mathrm{mH} / \mathrm{km}$ \\
\cline { 2 - 3 } & capacitance & $0.23 \mu \mathrm{F} / \mathrm{km}$ \\
\cline { 2 - 3 } & line length & Line $1: 100 \mathrm{~km}$, Line $2: 80 \mathrm{~km}$ \\
& Line $3: 100 \mathrm{~km}$, Line $4: 80 \mathrm{~km}$ \\
\hline
\end{tabular}

B. Simulation model of $D C$ grid

A simulation model of this 5-terminal DC grid is built on the MATLAB/Simulink platform in this paper. As the main purpose is to study the fault protection of DC grids, MMC converter is using average model as shown in Fig. 4, which can reduce the computational efforts which is needed by using detail switching model with a satisfactory precision accuracy [12].

The DCCB model, shown in Figure 5 is using Simulink arrester block to model the nonlinear resistance of the MOV.

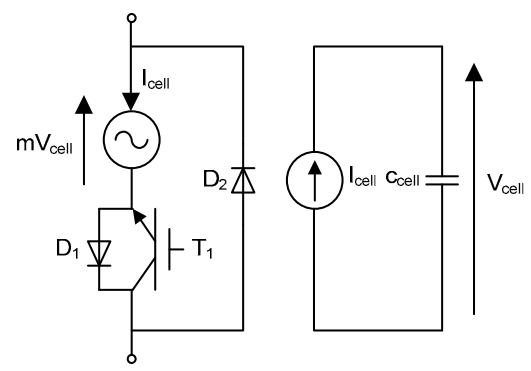

Fig. 4. Average model of MMC

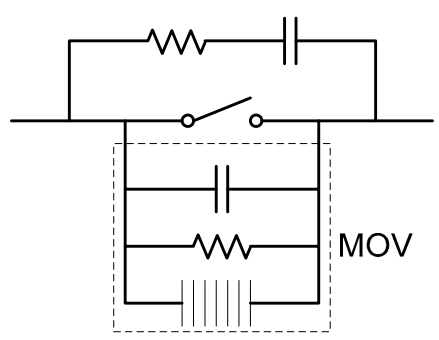

Fig. 5. Model of DCCB

In this configuration $\mathrm{Pi}$ model of transmission line cable has been used for the DC link.

\section{PROTECTION ARRANGEMENT AND STRATEGY OF DC GRID}

\section{A. Protection arrangement of $D C$ grid}

Similar with AC grid protection, the most simple protection method for DC grid is to install DCCBs at both ends of every DC lines. When a DC fault occurs, the DCCBs at faulty line open to isolate fault. However, this protection method will bring the following problems:
- A large number of DCCBs are needed, thus causing high cost;

- Due to the low impedance of DC grid, fault current rises very fast. If a DC fault happens in a DC grid, it may be difficult for DCCBs to detect the faulty line and disconnected it correctly. Therefore, this method is difficult to meet the requirements of "selectivity" and "reliability" for DC grid protection.

In the DC grid shown in Fig. 3, suppose there is a DC lineto-line fault occurred at the midpoint of Linel which connects station 1 and 3 at $1.1 \mathrm{~s}$, the obtained simulation results of fault currents $i_{1}$ and $i_{3}$ are represented in Fig. 6 . It can be seen that the amplitude and rate of rise of currents $i_{1}$ and $i_{3}$ are very close, and then the detection of fault and the trip of DCCBs may be difficult to act correctly.

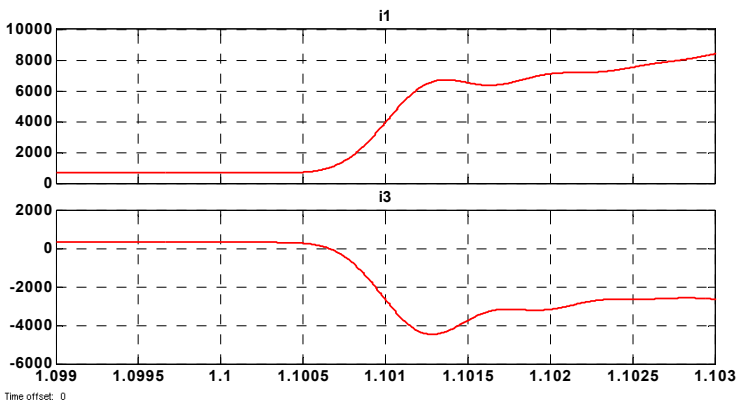

Fig. 6. Fault current value of $i_{1}$ and $i_{3}$ during line 1 fault

Considering the above problems, this paper proposes a zone protection arrangement for DC grid, which can not only reduce the number of DCCBs, but also ensure the reliable isolation of faulty zone and normal operation of healthy zone [13].

The 5-terminal DC gird in Fig. 3 is divided into three zones, as shown in Fig. 7. Three DC zones are interconnected by DC cables equipped with DCCBs, and there are no DCCBs in each DC zones in order to reduce the investment cost.

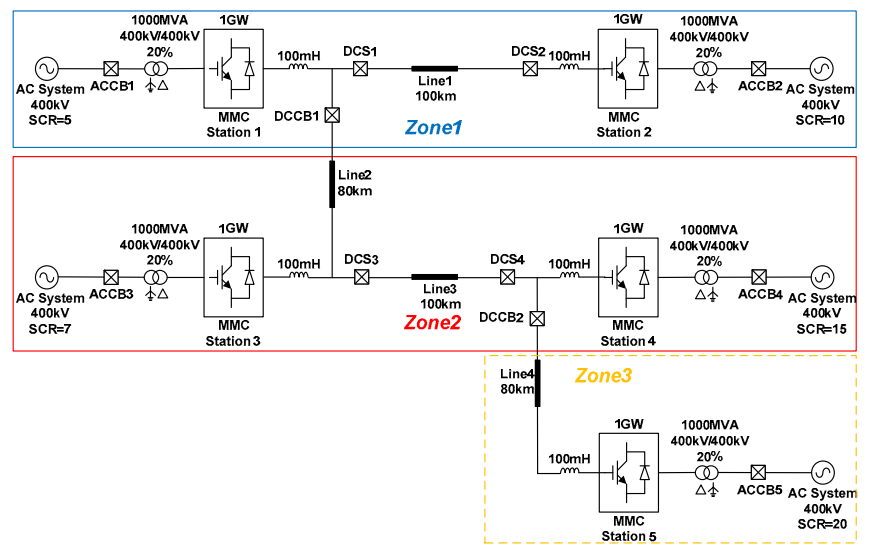

Fig. 7. Protection arrangement of 5-terminal DC gird

\section{B. Protection strategy of DC grid}

According to the protection requirement for DC grids, the following protection strategy is proposed to clear a DC fault: 
Step 1: use the local current measuring device to detect the fault current which is flowing through converter arms. If the arm current reaches its threshold protective level, converter will be blocked to protect the switching devices.

Step 2: use local current measurement approach to detect the fault current which is flowing through DCCBs. If the current amplitude exceeds twice of the rated current and the current rising rate reaches the preset value, a trip signal will be sent to the corresponding DCCB, allowing 3ms delay prior to the breaker being opened which representing the actuation delay. Thus, the isolation of faulty zone and healthy zone is done. Here, the formula for the rising rate of line current is [14]

$$
\frac{\mathrm{d} i}{\mathrm{~d} t}=\frac{V_{\text {terminal }}-V_{\text {line }}}{L}
$$

Where, $V_{\text {terminal }}$ represents $\mathrm{DC}$ link voltage at converter terminal, $V_{\text {line }}$ represents DC voltage at line side of DCCB, and $L$ represents the sum of current limiting reactance and internal reactance of DCCB.

An automatic fault detection method has been used for the DCCB trip, and to avoid false triggers caused during the detection stage has been eliminated by using mono-stable function on this detection method, as shown in Fig. 8.

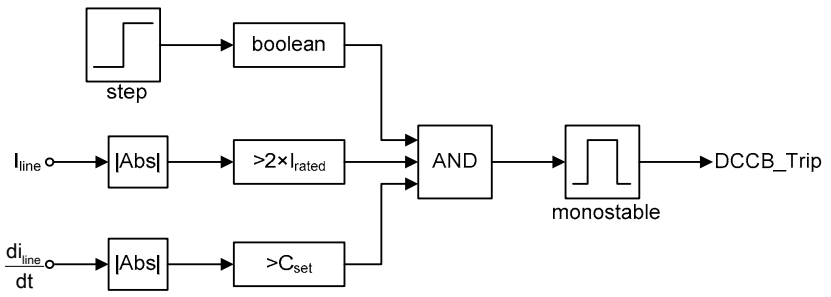

Fig. 8. Fault detection loop of DCCB

Step 3: open the ACCBs and DC switches to protect the faulty zone.

\section{Simulation study}

During normal operation, converter station 1 and 3 generate $800 \mathrm{MW}$ and $600 \mathrm{MW}$ power respectively and also have been assigned to control the active power of the stations. On the other hand station5 has been assigned to transmit 400MW power to the $\mathrm{AC}$ grid using active power control. Station2 and 4 have been designed to control the DC link voltage $(800 \mathrm{KV})$ of the entire DC grid. Station 2 and 4 have been designed as DC voltage (PI) control and DC voltage droop (P) control. In addition, each converter operates at unity power factor in order to simplify the analysis.

At the time instant of $1.1 \mathrm{~s}$, a DC line-to-line fault is applied at the midpoint of Line1 which connects station 1 and 3. The aforementioned protection strategy is applied to the DC grid shown in Fig. 7, and the obtained simulation results are shown in Fig. $9 \sim 11$.

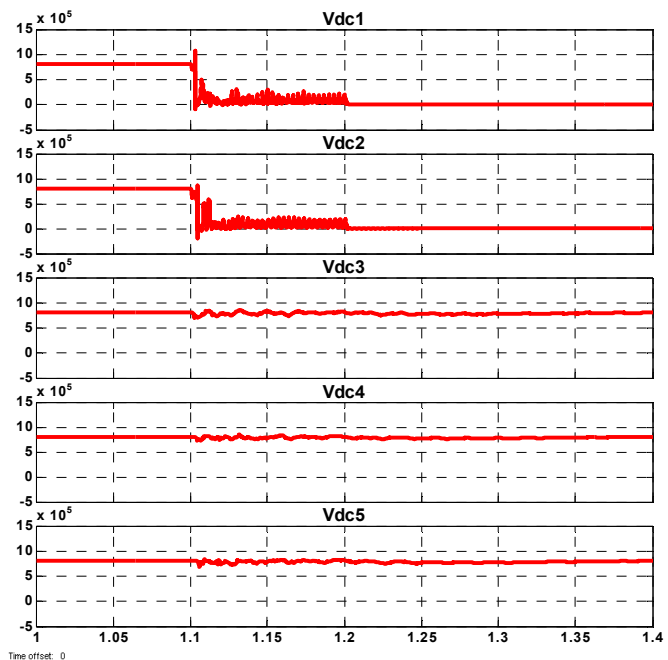

(a) DC link voltage at converter terminals

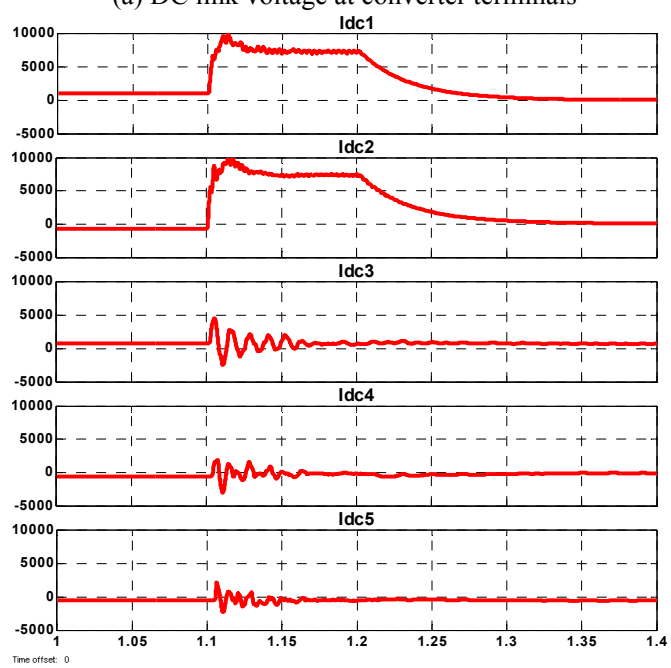

(b) DC link current at converter terminals

Fig. 9. DC system behavior during a DC fault

Fig. 9 illustrates how the DC link voltage and current magnitudes respond to the fault. It is evident that the existence of the DC fault will have severe impacts on the entire grid, causing DC voltages to decrease and DC currents to increase rapidly.

Fig. 10 shows the upper arm currents of MMC stations and the blocking of MMCs (where 0 represents blocking MMC, 1 represents unblocking $\mathrm{MMC}$ ). It can be seen that the arm currents of MMC1 and 2 increase rapidly due to the DC fault on Line1. When the arm current exceeds the current protection threshold, MMC will block. In this case, MMC1 and 2 block at $3.4 \mathrm{~ms}$ and $4.7 \mathrm{~ms}$ after the fault initiation, respectively. 


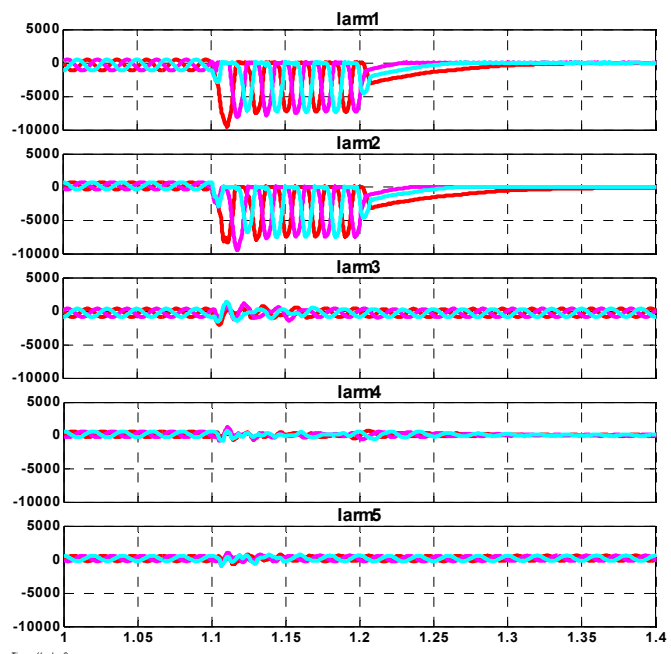

(a) Upper arm current of MMCs

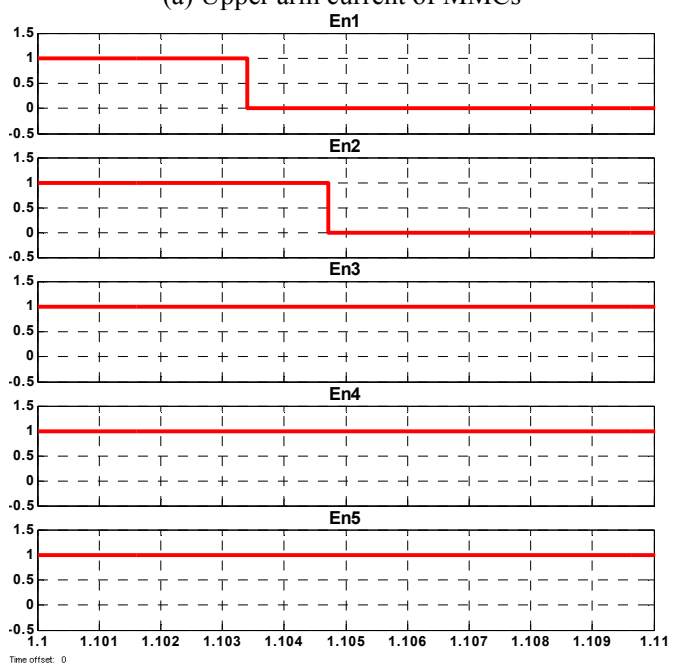

(b) Blocking of MMCs

Fig. 10. MMC behavior during a DC fault

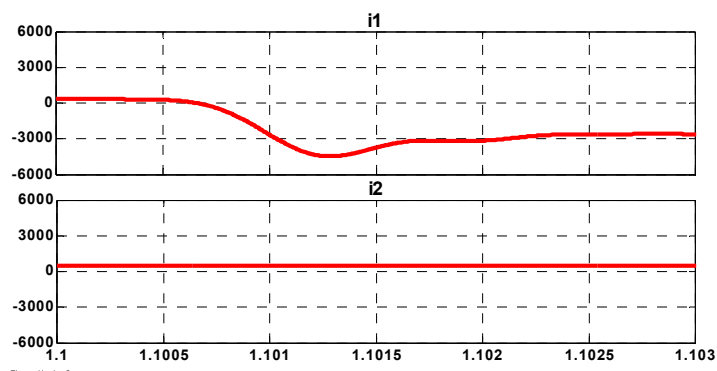

(a) DC current through DCCBs

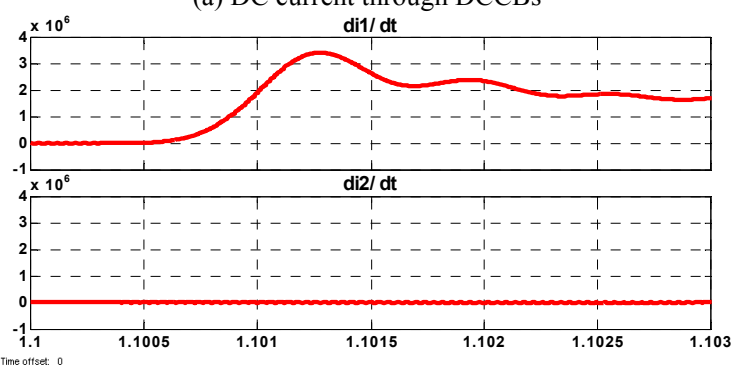

(b) DC current rising rate of DCCBs

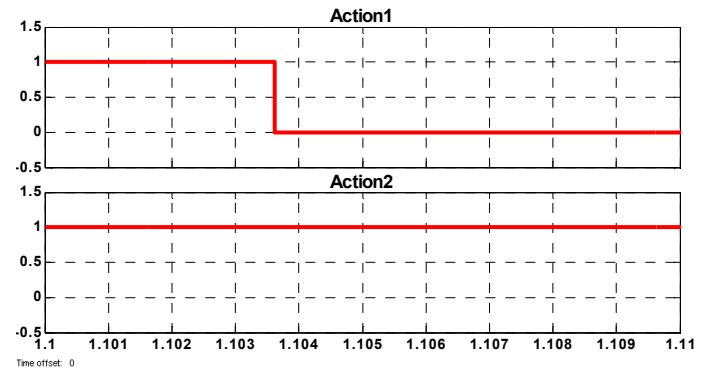

(c) Trip of DCCBs

Fig. 11. DCCB behavior during a DC fault

Fig. 11 shows the DC fault currents trough DCCBs and the trip of DCCBs (where 1 represents the close of DCCB, 0 represents the open of $\mathrm{DCCB}$ ). It can be seen that the $\mathrm{DC}$ current through DCCB1 increases rapidly. When the DC current exceeds the twice the rated current, a DC fault is confirmed. Also the rising rate of the current through DCCB1 reaches the peak value $3.41 \times 10^{3} \mathrm{kA}$ at $1.1013 \mathrm{~s}$, far beyond the preset value, thus a trip signal is sent to DCCB1. As can be seen from Fig. 11(c), DCCB1 opens at 1.1036s.

From Fig. 9 it can be seen that after the opening of DCCB1, station 3, 4 and 5 can resume normal operation, their DC link voltages and currents recover to steady-state value gradually. While station 1 and 2 is in fault zone, ACCBs and DC switches need to be used in zonel in order to isolate the DC fault completely. After disconnect ACCBs and DC switches, the DC link voltages and currents of station 1 and 2 will reduced to 0 .

It can be seen that after the opening of DCCB1, the DC grid is split into two isolated DC zones. The healthy zone (i.e. Zone 2 and 3 in Fig.7) can maintain normal operation, while the faulty zone (i.e. Zone1) is protected by ACCBs and DC switches.

In addition, the loss of a transmission line due to fault results in a reduction in overall power capacity of the DC grid. This has a direct consequence on the remaining healthy lines of the DC grid and proper power rescheduling will be required to ensure stable system operation.

\section{CONCLUSION}

DC fault protection of a DC grid has emerged as the critical issue at present due to the low impedance of DC grids. DC network partition with DCCBs at strategic locations are proposed and studied in this paper. This protection arrangement can minimize the number of DCCBs required in DC grid with tolerable effect of DC faults. The faulty DC zone is isolated using DCCBs allowing the healthy DC section to recover and restore quickly while the faulty zone is protected by ACCBs and DC switches. The partition of DC grid is influenced by several factors, smaller DC zone means smaller effect area of DC grid but higher investment cost and lower protection selectivity. Thus, the choice of protection arrangement should be decided according to the protection requirements of the actual DC grid. This paper built a simulation model of 5-terminal DC grid, and then verified the protection arrangement and strategies by simulation. The 
simulation results corresponding to DC fault protection have been presented give a satisfactory result. The concept of this protection methods proposed in this paper can be extend easily to DC grids with more terminals.

\section{REFERENCES}

[1] Yao Liangzhong, Wu Jing, Wang Zhibing, et al, "Pattern Analysis of Future HVDC Grid Development," Proceedings of the CSEE, vol. 34, pp. 6007-6020 (in Chinese).

[2] A. Lesnicar and R. Marquardt, "An innovative modular multilevel converter topology suitable for a wide power range", Proc. 2003 IEEE Power Tech Conference, Bologna, 2003.

[3] E. Kontos, R. T. Pinto, S. Rodrigues, and P. Bauer, "Impact of HVDC Transmission System Topology on Multiterminal DC Network Faults," IEEE Trans. on Power Delivery, vol. PP, pp. 1-1, 2014.

[4] X. Yan, S. Difeng, and Q. Shi, "Protection coordination of meshed MMC-MTDC transmission systems under DC faults," in TENCON 2013 - 2013 IEEE Region 10 Conference (31194), 2013, pp. 1-5.

[5] N. Yousefpoor, S. Kim, and S. Bhattacharya, "Control of voltage source converter based multi-terminal DC grid under DC fault operating condition," in Energy Conversion Congress and Exposition (ECCE), 2014 IEEE, 2014, pp. 5703-5708.

[6] L. Tang and B.-T. Ooi, "Protection of VSC-multi-terminal HVDC against DC faults," in Power Electronics Specialists Conference, 2002. pesc 02. 2002 IEEE 33rd Annual, 2002, vol.2, pp. 719-724.
[7] J. Yang, J. E. Fletcher, and J. O'Reilly, "Multiterminal DC Wind Farm Collection Grid Internal Fault Analysis and Protection Design," IEEE Trans. on Power Delivery, vol. 25, pp. 2308-2318, 2010.

[8] H. Liu, Z. Xu, and Y. Huang, "Study of protection strategy for VSC based HVDC system," in Transmission and Distribution Conference and Exposition, 2003 IEEE PES, 2003, Vol.1, pp. 49-54.

[9] L. Tang and B.-T. Ooi, "Locating and Isolating DC Faults in MultiTerminal DC Systems," IEEE Trans. on Power Delivery, vol. 22, pp. 1877-1884, 2007.

[10] Y. Jin, J. E. Fletcher, and J. O'Reilly, "Short-Circuit and Ground Fault Analyses and Location in VSC-Based DC Network Cables," IEEE Trans. on Industrial Electronics vol. 59, pp. 3827-3837, 2012.

[11] J. Rafferty, L. Xu, and D. J. Morrow, "DC fault analysis of VSC based multi-terminal HVDC systems," in AC and DC Power Transmission (ACDC 2012), 10th IET International Conference on, 2012, pp. 1-6.

[12] R. Zeng, L. Xu, L. Yao, "DC/DC Converters Based on Hybrid MMC for HVDC Grid Interconnection," in 11th IET International Conference on AC and DC Power Transmission,Birmingham, 2015, pp. 1-6.

[13] Md Habibur Rahman, Lie Xu, Liangzhong Yao, "DC Fault Protection Strategy Considering DC Network Partition", to be appeared in 2016 IEEE PES General Meeting, July 17-21, 2016, Boston, USA.

[14] J. Sneath, A. D. Rajapakse, "Fault Detection and Interruption in an Earthed HVDC Grid using ROCOV and Hybrid DC Breakers," IEEE Trans. on Power Delivery vol. 99, pp. 1-8, 2014. 